\title{
Range of confining pressures for the Hoek-Brown criterion
}

1 Benoît Latapie Eur Ing, MSc

Technical Manager, Ground Engineering, WS Atkins \& Partners Overseas, Dubai, UAE (corresponding author: benoit.latapie@atkinsglobal.com)
2 Andrew L. E. Lochaden CEng, MIEl, PhD

Geotechnical Engineer, Ground Engineering, WS Atkins \& Partners Overseas, Dubai, UAE
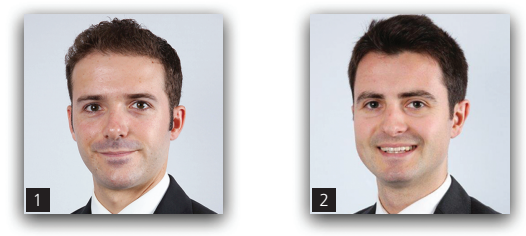

Engineering in weak rock using modern, computer-based design techniques is notoriously challenging because the laboratory tests and classification methods routinely carried out on such materials yield rock parameters. Such parameters are not directly compatible with the most widely used constitutive model of those computer-based methods - that is, the Mohr-Coulomb failure envelope. There is no direct relationship between Mohr-Coulomb (linear) and Hoek-Brown (non-linear) parameters, and marrying those two failure envelopes is notoriously difficult. When formulating a failure criterion for rock materials, based on rock and rock mass parameters, a correlation with the Mohr-Coulomb failure criterion has been proposed, which can be obtained from the computer program RocLab. One of the essential input parameters for such correlation is called the maximum confining pressure. This parameter directly affects the correlated shear strength parameters on the Mohr-Coulomb failure envelope and hence choosing it with care is the key to producing a safe, yet economic design. The present paper discusses the use of several methods for determining the maximum confining pressure to derive Mohr-Coulomb parameters for weak rock in slope and retaining wall applications. The suitability of each method considered is discussed against the results of back analyses, and design recommendations are proposed.

\section{Notation}

$c^{\prime} \quad$ cohesion

$F_{\mathrm{S}} \quad$ factor of safety

GSI geological strength index

$H \quad$ slope height

$k_{0} \quad$ coefficient of at-rest earth pressures

$k_{\mathrm{h}} \quad$ horizontal seismic coefficient

$k_{\mathrm{v}} \quad$ vertical seismic coefficient

$m_{\mathrm{i}} \quad$ rock material constant

$\gamma$ density

$\sigma_{3}^{\prime} \quad$ confining pressure

$\sigma_{3 \max }^{\prime}$ maximum confining pressure

$\sigma_{3 \min }^{\prime}$ minimum confining pressure

$\sigma_{\mathrm{cm}}^{\prime}$ global rock mass strength

$\sigma_{\mathrm{ci}} \quad$ unconfined compressive strength (UCS)

$\phi^{\prime} \quad$ angle of internal friction

\section{Introduction}

The engineering behaviour of weak rocks with unconfined compressive strengths (UCSs) towards the lower end of the rock competency scale (defined as UCS $<15 \mathrm{MPa}$ by Carter et al. (2008)) is notoriously challenging to estimate accurately as such materials sit in an intermediate category, between rock and soil, often labelled as intermediate geomaterial (IGM). With regard to slope and retaining wall applications, the behaviour of weak, weathered rock at the lower end of the competency scale is generally controlled by the overall shear strength of the rock mass, rather than by discontinuities, as is often the case for hard, more intact rocks. Hence, it seems logical, for slope and retaining wall applications in weak rock, to approximate rock behaviour using the Mohr-Coulomb failure criterion rather than hard rock constitutive models. It is also beneficial to use Mohr-Coulomb, as it is a computer modelling industry standard. The suitable selection of the maximum confining pressure is essential to the successful realisation of this approach.

\section{Confining pressure - definition}

The way confining pressure is defined in the literature varies and usually relates to either vertical or horizontal ground stresses. Confining pressure is sometimes cited as a synonym of 'vertical stress', 'lithostatic pressure' or 'overburden pressure'.

The confining pressures adopted in laboratory testing of soil/rock samples constitute the representation of their in situ condition. 
The determination of the coefficient of at-rest earth pressures $k_{0}$ in rock materials, based on testing, is notoriously difficult and, thus, differentiating vertical and horizontal confining pressures in rock is prone to errors. In addition, most laboratory testing apparatuses that allow for applying a confining pressure to the sample are generally limited to one confining pressure. This means that one may choose between vertical and horizontal confining pressures when carrying out such tests, or carry out multiple tests using a range of confining pressures applicable to the corresponding engineering situation.

For slope and retaining wall applications, the orientation of the major and minor principal stresses is likely to vary, following the geometry of the preferential plane of failure. This means that the confining pressure in the appropriate position, during excavation, will be a combination of vertical and horizontal stresses.

The choice of confining pressure when deriving Mohr-Coulomb parameters from the Hoek-Brown failure criterion is supposed to cover a range of values representative of the engineering application and predominant rock failure mechanism. The use of the vertical effective stress is widely recognised as a reasonable approximation of the confining pressure in the appropriate position for slope and retaining wall application in weak rock material (or IGM) when deriving Mohr-Coulomb parameters from the Hoek-Brown failure criterion.

\section{The role of confining pressure when deriving Mohr-Coulomb parameters from the Hoek-Brown failure criterion}

The information presented in this section is consistent with that presented by Brown (2008), Hoek and Brown (1997) and Hoek and Marinos (2007).

In order to match the Mohr-Coulomb failure envelope to the nonlinear one from Hoek-Brown, the range of applicable confining pressures $\left(\sigma_{3}^{\prime}\right)$ must be defined. Setting such a range means that the portion of the Hoek-Brown failure envelope outside of the range of applicable confining pressures $\left[\sigma_{3 \min }^{\prime} ; \sigma_{3 \max }^{\prime}\right]$ is ignored when performing the curve-fitting exercise of the remaining Hoek-Brown failure envelope with Mohr-Coulomb parameters.

Zero is often taken as the minimum value (this is actually the default input in the RocLab program and cannot be changed by the user), whereas the maximum value $\left(\sigma_{3 \max }^{\prime}\right)$ is selected depending on the specific engineering application. The choice of the maximum confining pressure should be such that it helps to create a bracket that contains the range of representative stresses the strata is likely to undergo during its loading in response to a specific engineering application.

Hoek et al. (2002) introduced the concept of the global rock mass strength and proposed the following relationship to estimate it from Mohr-Coulomb parameters
1. $\sigma_{\mathrm{cm}}^{\prime}=\frac{2 c^{\prime} \cos \phi^{\prime}}{1-\sin \phi^{\prime}}$

where $\phi^{\prime}$ is the internal friction angle in degrees and $c^{\prime}$ is the cohesion in kilopascals.

The corresponding relationship for Hoek-Brown parameters is as follows

2. $\sigma_{\mathrm{cm}}^{\prime}=\sigma_{\mathrm{ci}} \times \frac{\left[m_{\mathrm{b}}+4 s-a\left(m_{\mathrm{b}}-8 s\right)\right]\left[\left(m_{\mathrm{b}} / 4\right)+s\right]^{a-1}}{2(1+a)(2+a)}$

where $a, m_{\mathrm{b}}$ and $s$ are the Hoek-Brown parameters defined by Hoek et al. (2002). The following notation is used henceforth: $\sigma_{\mathrm{cm}}^{\prime}(\mathrm{M}-\mathrm{C})$ and $\sigma_{\mathrm{cm}}^{\prime}(\mathrm{H}-\mathrm{B})$ correspond to Equations 1 and 2 respectively.

The relationships from Equations 1 and 2 have been used to plot the global rock mass strength as a function of the maximum confining pressure. As illustrated in Figure 1, the choice of the range of confining pressures has a direct impact on the overall rock mass shear strength when modelled using Mohr-Coulomb parameters. However, the same is not true for Hoek-Brown parameters, where the rock mass strength is independent of the confining pressure.

Figure 1 illustrates the evolution of the two failure criteria as a function of the maximum confining pressure.

It is noteworthy from Figure 1 that the rock mass strengths estimated from Mohr-Coulomb and Hoek-Brown are equal only for a maximum confining pressure equal to UCS/4. The global rock mass strength from Mohr-Coulomb parameters is underestimated for maximum confining pressures lower than UCS/4, compared with the Hoek-Brown rock mass strength. The global rock mass strength from Mohr-Coulomb parameters is overestimated for maximum confining pressures higher than UCS/4, compared with the Hoek-Brown rock mass strength. When using the computer program RocLab, using a maximum confining pressure of UCS/4 corresponds to selecting 'General' in the 'Application' tab of the software, as illustrated in Figure 2.

As explained by Hoek et al. (2002), the value of $\sigma_{3 \max }^{\prime}$ must not exceed UCS $/ 4$, after which the equivalent Mohr-Coulomb parameters would correspond to a higher rock mass strength $\left(\sigma_{\mathrm{cm}}^{\prime}\right)$, which would lead to unrealistic predictions of the rock mass behaviour in shear.

In addition, the results of a sensitivity analysis are presented in Figure 3 to illustrate the effect of different maximum confining pressures on the curve-fitting exercise of portions of the Hoek-Brown failure criterion with Mohr-Coulomb parameters. In this example, the relationship proposed by Hoek et al. (2002) to determine the maximum confining pressure for slope application was used. Further details of this method are presented in the next section. 


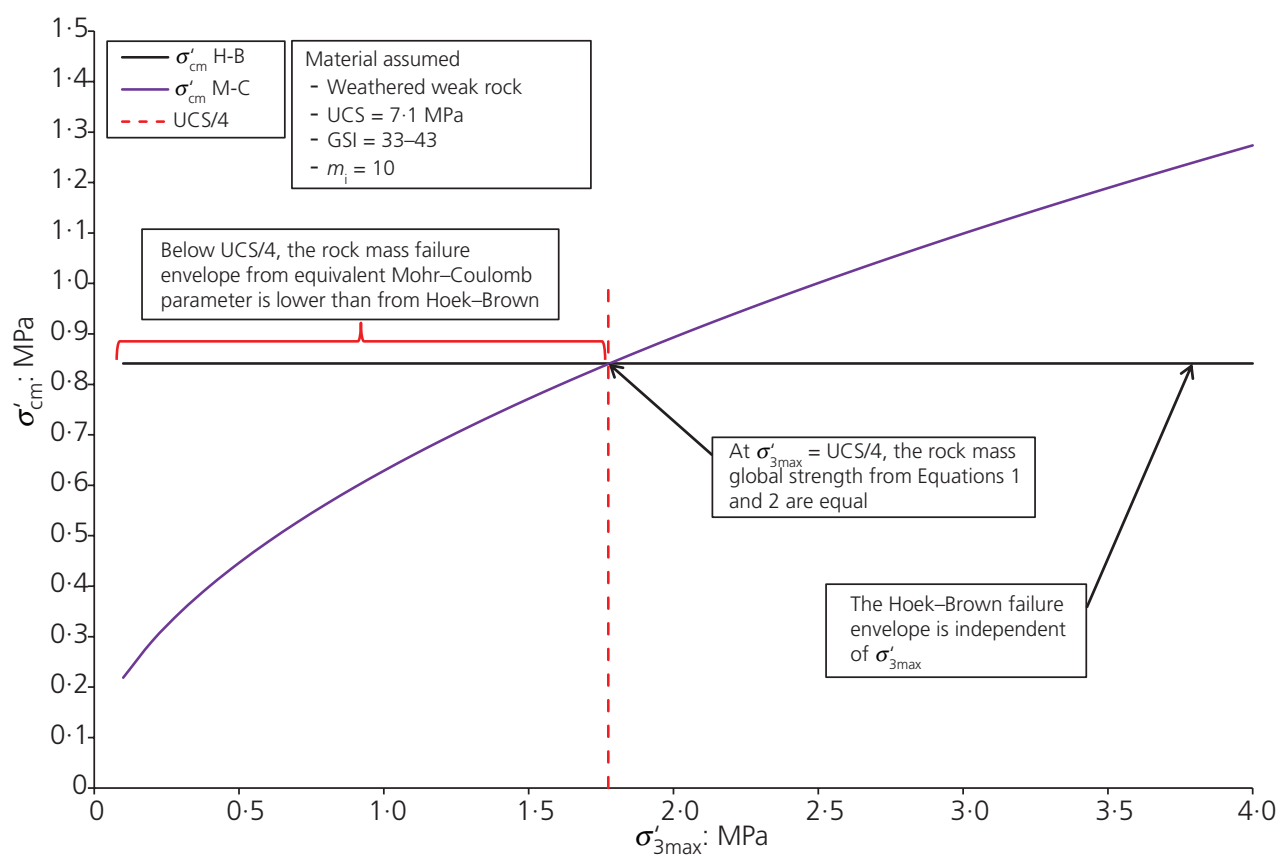

Figure 1. $\sigma_{\mathrm{cm}}^{\prime}$ as a function of $\sigma_{3 \max }^{\prime}$ for Hoek-Brown and Mohr-Coulomb failure envelopes

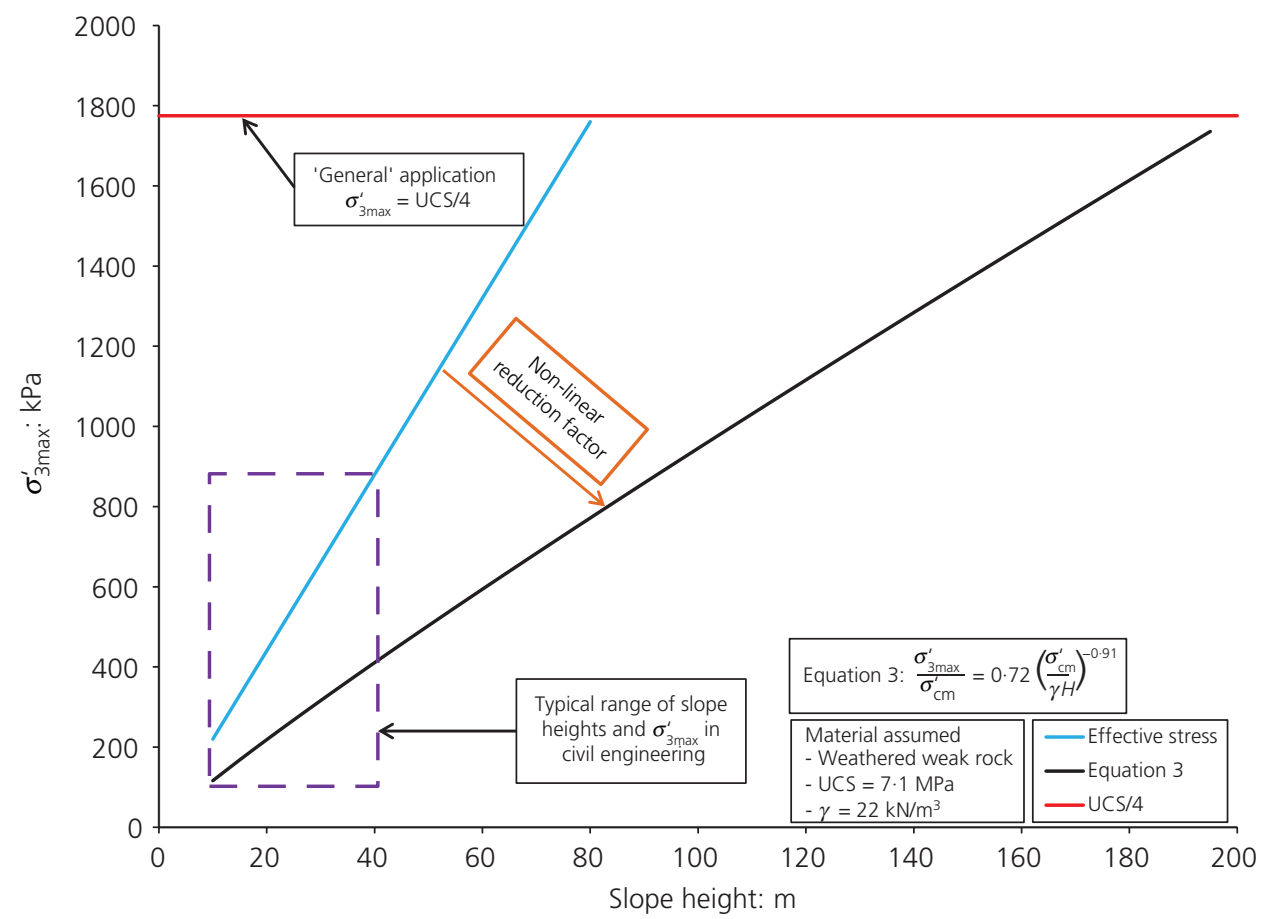

Figure 2. $\sigma_{3 \max }^{\prime}$ as a function of the slope height

Figure 3 shows, for a slope application, how the analogy evolves with the slope height, or increases in maximum confining pressure. The information presented in Figure 3 uses three different ranges of $\left[0 ; \sigma_{3 \max }^{\prime}\right]$ where each value of $\sigma_{3 \max }^{\prime}$ corresponds to an assumed slope height. The range of confining pressure is used to define the portion of the Hoek-Brown failure envelope used to derive three different sets of Mohr-Coulomb parameters. It is evident that for the same rock mass properties, the deeper the 


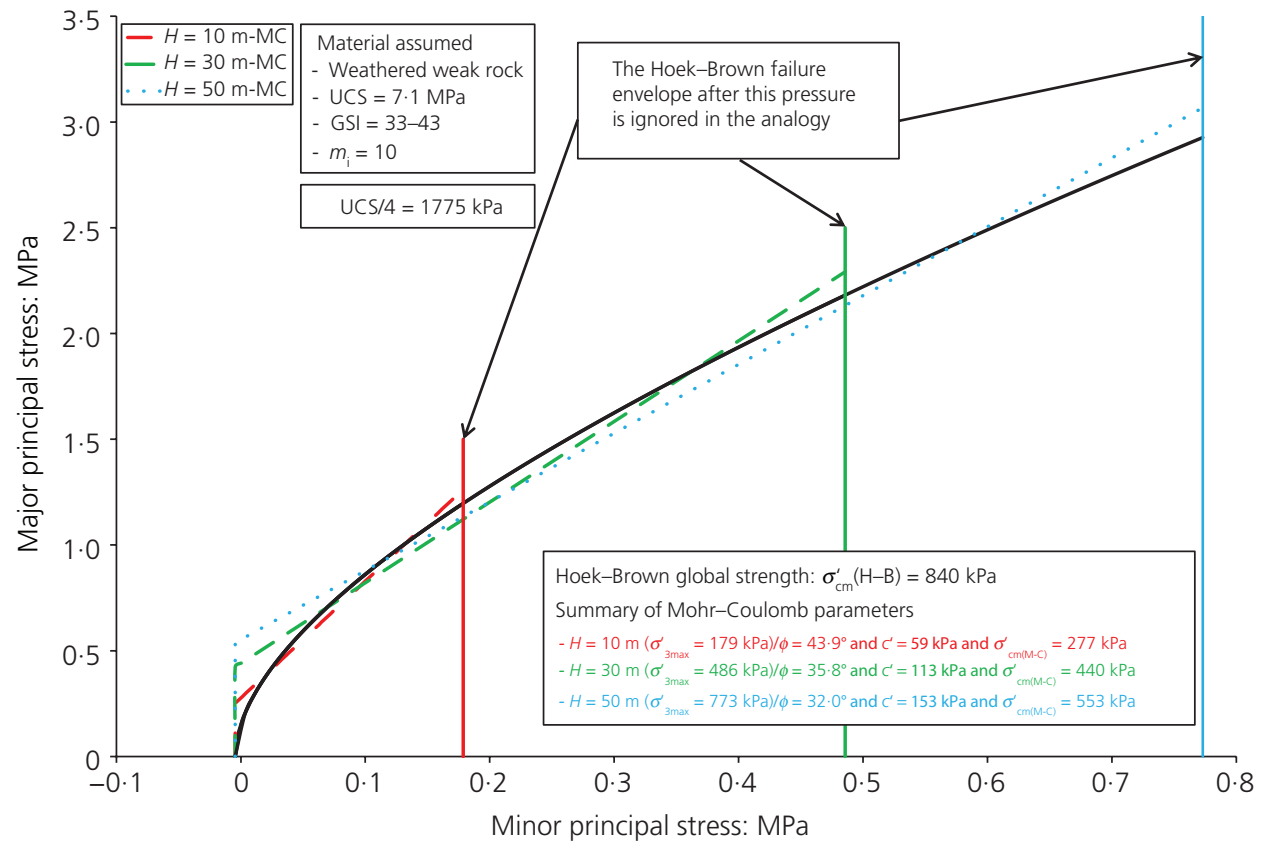

Figure 3. Dependency of the Mohr-Coulomb analogy on the confining pressure

cut slope, the higher the global rock mass strength that may be considered in design.

\section{Method considered for the determination of the range of confining pressures}

Experience working on different projects, where Mohr-Coulomb parameters derived from the Hoek-Brown failure envelope were required, revealed an array of different methods used in the industry for selecting the value of maximum confining pressure when using the RocLab software.

In this paper, the authors propose to compare/benchmark the results of three different methods (selected based on what seems to be most commonly used in the industry) for defining the maximum confining pressure when deriving Mohr-Coulomb parameters from the Hoek-Brown failure envelope. Recommendations on these methods are provided in the final section.

In order to compare the results obtained with the different methods considered, a set of common assumptions has been defined, matching what is normally required on civil engineering projects, as follows.

- A $20 \mathrm{kPa}$ uniformly distributed load is applied at ground level.

- An open-cut excavation of a rock slope with dewatering, the groundwater level is below the critical slip's shear plane and below the base of the excavation. Hence, the effective stress present along the critical plane of failure is equal to the total stress.

- The excavation depth is $30 \mathrm{~m}$ and the excavation slope is identical in all models.
- Seismic loads have been considered by using the following horizontal and vertical coefficients, respectively: $k_{\mathrm{h}}=0 \cdot 042$ and $k_{\mathrm{v}}=-0 \cdot 021$

- The stratigraphy has been split into three different layers of the same weathered rock material, with identical properties (as shown in Figure 4). This is to enable the derivation of different maximum confining pressures for each of these layers. It also allows results to be obtained which are independent of the strength properties of the materials considered, and direct comparison of the various methods used.

- The software used to carry out the slope stability analyses is Slope/W from the Geoslope package.

The sections hereafter detail the different methods considered in this note and how the minimum and maximum confining pressures are determined.

Method A: as proposed by Hoek et al. (2002)

Method A corresponds to the recommendation provided by Hoek et al. (2002). This means that the following relationships are recommended to calculate the maximum confining pressure for slope application

3. $\frac{\sigma_{3 \max }^{\prime}}{\sigma_{\mathrm{cm}}^{\prime}}=0.72\left(\frac{\sigma_{\mathrm{cm}}^{\prime}}{\gamma H}\right)^{-0.91}$

where $\sigma_{\mathrm{cm}}^{\prime}$ is the rock mass strength (calculated with the Hoek-Brown failure criterion), $\gamma$ is the unit weight of the rock 


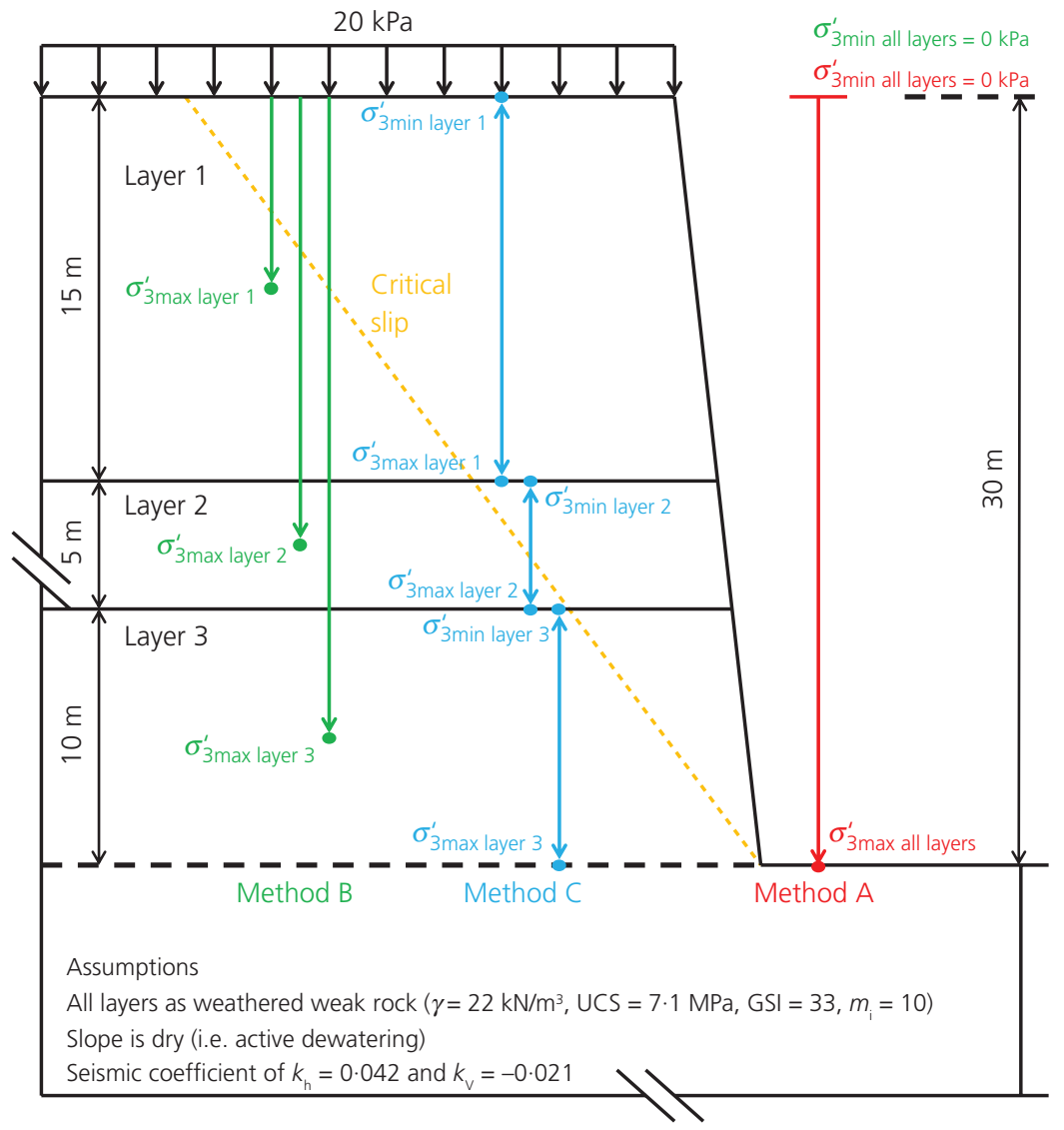

Figure 4. Summary of all three methods considered

mass and $H$ is the height of the slope. Note that with this method, only the overall slope height is considered in deriving the maximum confining pressure; relative thicknesses of different stratigraphy units are not considered. In this method, the minimum confining pressure is taken as zero.

Figure 2 provides a visual representation of Equation 3, with different values of $\sigma_{3 \max }^{\prime}$ for a varying slope height. The figure also shows the evolution of the total stress with the slope height, which illustrates the non-linear nature of the reduction factor incorporated in Equation 3 compared with an effective stress calculation.

The rest of the parameters are fixed and highlighted in Figure 2. The zone corresponding to the majority of civil engineering applications has also been highlighted.

The red line plotted in Figure 2 corresponds to the General Application option of the RocLab program when selecting the maximum confining pressure to use. The general application corresponds to the value of $\mathrm{UCS} / 4$, which is the maximum recommended confining pressure when approximating the Hoek-Brown failure criterion with Mohr-Coulomb parameters.
Method B: $\sigma_{3 \max }^{\prime}$ is taken at the mid-point of each layer Method B uses a different confining pressure for each unit of strata composing the cut slope. The maximum confining pressure is taken as the total stress at the mid-point of the soil/rock layer. A different maximum confining pressure is selected for each stratigraphy layer. All minimum confining pressures are set to $0 \mathrm{kPa}$.

An alternative to this method uses the depth of the mid-point of the layer as the input value for the $H$ parameter in the Hoek-Brown failure criterion in RocLab, using the Slope application (i.e. Equation 3). This means that the reduction factor generated by Equation 3 is added to the conservative omission of the range of confining pressures over the bottom mid-height of the layer. This appears unduly conservative compared with the actual total stress present at mid-height of the soil/rock layer. This alternative is not presented with the results of the analysis as it leads to approximately $10 \%$ underestimation of the slope's factor of safety $\left(F_{\mathrm{S}}\right)$ for the cases considered.

Method C: $\sigma_{3 \min }^{\prime}$ and $\sigma_{3 \max }^{\prime}$ are taken at the top and the bottom of each layer respectively

Method C is a refinement of Method B in the sense that strataspecific confinement pressures are derived but both the minimum 
and maximum confining stresses for the soil/rock layer are defined. In other terms, it uses the depth to the bottom of each layer to define the layer's maximum confining pressure $\left(\sigma_{3 \max }^{\prime}\right)$, and the depth to the top of the layer to define the layer's minimum confining pressure $\left(\sigma_{3 \min }^{\prime}\right)$, by calculating the total stress present at these locations. The calculation of the range of confining pressures for this method and the derivation of Mohr-Coulomb parameters were done manually. The Hoek-Brown failure envelope was truncated to keep the curve between the minimum and maximum confining pressures, and Mohr-Coulomb parameters were obtained using the curve-fitting method from the Hoek-Brown criterion, after Hoek et al. (2002).

Figure 4 summarises the three methods outlined above in deriving confining pressures for the estimation of Mohr-Coulomb parameters.

\section{Model undrained: Hoek-Brown rock mass strength}

Model undrained uses an undrained constitutive model with the Hoek-Brown global strength as equivalent undrained shear strength; this is simply for comparison with the three effective stress methods presented.
Summary of range of confining pressures $\left[\sigma_{3 \min }^{\prime} ; \sigma_{3 \max }^{\prime}\right]$ All three methods were used to derive equivalent Mohr-Coulomb parameters using RocLab. The main input parameters to RocLab are summarised in Figure 4. In addition, Table 1 summarises the different ranges of confining pressures used to derive Mohr-Coulomb parameters.

The software Slope/W has been used to carry out slope stability analyses for all methods considered. The Slope/W software is part of the Geoslope package. It employs limit-equilibrium methods such as Bishop's simplified, Janbu's simplified and Spencer and Morgenstern-Price methods. Each method is computed simultaneously so that the method giving the critical estimate of stability is identified. The analyses, assumptions and geometry (as summarised in Figure 2) were kept consistent between the different models so that the results are directly comparable.

\section{Results}

Table 2 presents the input to and the results from the slope stability analysis carried out using Slope/W.

\begin{tabular}{|c|c|c|c|c|}
\hline \multirow[t]{2}{*}{ Ref. } & \multirow[t]{2}{*}{ Method } & \multicolumn{3}{|c|}{$\left[\sigma_{3 \min }^{\prime} ; \sigma_{3 \max }^{\prime}\right]: \mathrm{kPa}$} \\
\hline & & Layer 1 & Layer 2 & Layer 3 \\
\hline$A$ & Equation 3 & {$[0 ; 486]$} & {$[0 ; 486]$} & {$[0 ; 486]$} \\
\hline B & Effective stress & {$[0 ; 165]$} & {$[0 ; 385]$} & {$[0 ; 550]$} \\
\hline C & Effective stress & {$[0 ; 330]$} & {$[330 ; 440]$} & {$[440 ; 660]$} \\
\hline
\end{tabular}

Table 1. Summary of confining pressure ranges to derive Mohr-Coulomb parameters

\begin{tabular}{|c|c|c|c|c|c|c|c|c|}
\hline Method & Layer & $\phi^{\prime}:{ }^{\circ}$ & $c^{\prime}: \mathrm{kPa}$ & $\sigma_{\mathrm{cm}}^{\prime}(\mathrm{M}-\mathrm{C}): \mathrm{kPa}$ & $\sigma_{\mathrm{cm}}^{\prime}(\mathrm{H}-\mathrm{B}): \mathrm{kPa}$ & $\sigma_{c m}^{\prime}$ Ratio $^{a}: \%$ & $F_{S}$ & Diff. $^{\text {b. }} \%$ \\
\hline$A$ & - & $36 \cdot 0$ & 113 & 441 & 840 & 53 & $1 \cdot 25$ & N/A \\
\hline B & 1 & $44 \cdot 5$ & 56 & 267 & 840 & 32 & 1.06 & -15 \\
\hline B & 2 & $37 \cdot 7$ & 97 & 395 & 840 & 47 & 1.06 & -15 \\
\hline B & 3 & $34 \cdot 8$ & 122 & 466 & 840 & 56 & 1.06 & -15 \\
\hline C & 1 & 38.9 & 87 & 364 & 840 & 43 & $1 \cdot 26$ & $<1 \cdot 0$ \\
\hline C & 2 & $36 \cdot 5$ & 120 & 476 & 840 & 57 & $1 \cdot 26$ & $<1 \cdot 0$ \\
\hline $\mathrm{C}$ & 3 & $33 \cdot 4$ & 162 & 602 & 840 & 72 & $1 \cdot 26$ & $<1 \cdot 0$ \\
\hline Undrained & - & N/A & N/A & N/A & 840 & N/A & 4.95 & N/A \\
\hline
\end{tabular}

${ }^{\mathrm{a}} \sigma_{\mathrm{cm}}^{\prime}$ ratio $=100 \times\left[\sigma_{\mathrm{cm}}^{\prime}(\mathrm{M}-\mathrm{C}) / \sigma_{\mathrm{cm}}^{\prime}(\mathrm{H}-\mathrm{B})\right]$

${ }^{\mathrm{b}}$ Diff. is the percentage difference of the factor of safety compared to what is obtained with Method A

Table 2. Summary of Mohr-Coulomb parameters and Slope/W

results 


\section{Comments on the results}

- Using Method A for a 30-m-high slope means that only $53 \%$ of the Hoek-Brown global strength is used in the Mohr-Coulomb analogy.

- Method B yields lower Mohr-Coulomb global strengths (average $\sigma_{\mathrm{cm}}^{\prime}$ ratios, weighted with the thickness of each rock layer, of $42.5 \%$ ) compared with Method A. In turn, the $F_{\mathrm{S}}$ on the slope stability with Method B are 15\% lower than with Method A.

- Method C yields an average, weighted with the thickness of each rock layer, of $55 \%$ for the $\sigma_{\mathrm{cm}}^{\prime}$ ratio, which is almost identical to the ratio obtained with Method A. In turn, the $F_{\mathrm{S}}$ on the slope stability are also almost identical for both Methods A and C.

- The undrained analysis that uses the full amount of global rock mass strength from the Hoek-Brown criterion leads to a very large $F_{\mathrm{S}}$, compared with the effective stress methods.

\section{Conclusions and recommendations}

When comparing all the methods presented in this paper, the authors have concluded the following

- Method C is the most theoretically correct method in determining layer-specific confining pressures to derive Mohr-Coulomb parameters from the Hoek-Brown failure criterion as it considers ranges of confining pressures specific to each rock layer.

- Method B is conservative and, although layer specific, this method seems to yield a less accurate analogy as relevant ranges of confining pressures are ignored.

- Method A is by far the simplest of all the envisaged methods and yields almost identical results to Method C.

Based on the results obtained in this study, the following approach may be used in design. Method A is deemed appropriate for use in slope applications where the different rock units controlling the slope stability have similar strength properties and similar densities. For such situations, Method $\mathrm{C}$ may also be used but will require additional calculation time to yield a very similar $F_{\mathrm{S}}$ to Method A. In situations where one of the rock layers constituting the slope's stratigraphy has much lower strength properties than the other layers, using Method A may lead to overestimating the slope's $F_{\mathrm{S}}$ against failure. In such cases, the authors recommend using Method $\mathrm{C}$ to ensure a more accurate prediction and to avoid overestimation. Method B is not recommended as it is unduly conservative.

\section{REFERENCES}

Brown ET (2008) Estimating the mechanical properties of rock masses. In Proceedings of the 1st Southern Hemisphere International Rock Mechanics Symposium, Perth, Australia, vol. 1, pp. 3-22.

Carter TG, Diederichs MS and Carvalho JL (2008) Application of modified Hoek-Brown transition relationships for assessing strength and post-yield behaviour at both ends of the rock competence scale. Journal of the Southern African Institute of Mining and Metallurgy 108(6): 325-337.

Hoek E and Brown ET (1997) Practical estimates of rock mass strength. International Journal of Rock Mechanics and Mining Sciences 34(8): 1165-1186, http://dx.doi.org/10.1016/S13651609(97)80069-X.

Hoek E and Marinos P (2007) A brief history of the development of the Hoek-Brown failure criterion. Soils and Rocks 2. See https://roscience.com/documents/hoek/references/ H2007.pdf (accessed 09/02/2016).

Hoek E, Carranza-Torres C and Corkum B (2002) Hoek-Brown failure criterion - 2002 edition. In NARMS-TAC 2002: Mining and Tunnelling Innovation and Opportunity. Proceedings of the 5th North American Rock Mechanics Society Meeting and 17th Tunnelling Association of Canada Conference (Hammah R, Bawden W, Curran J and Telesnicki M (eds)). University of Toronto Press, Toronto, Canada, vol. 1, pp. 267-273.

\footnotetext{
WHAT DO YOU THINK?

To discuss this paper, please submit up to 500 words to the editor at journals@ice.org.uk. Your contribution will be forwarded to the author(s) for a reply and, if considered appropriate by the editorial panel, will be published as a discussion in a future issue of the journal.
} 